\title{
Learning and Practising to Use Digital Cameras in Early Childhood Classrooms
}

\author{
Kamariah Abu Bakar \\ Faculty of Education, Universiti Kebangsaan Malaysia, Bangi, Selangor, Malaysia \\ Email: kamariah_abubakar@ukm.edu.my
}

How to cite this paper: Bakar, K. A. (2021). Learning and Practising to Use Digital Cameras in Early Childhood Classrooms. Creative Education, 12, 1323-1332. https://doi.org/10.4236/ce.2021.126100

Received: May 19, 2021

Accepted: June 18, 2021

Published: June 21, 2021

Copyright (c) 2021 by author(s) and Scientific Research Publishing Inc. This work is licensed under the Creative Commons Attribution International License (CC BY 4.0).

http://creativecommons.org/licenses/by/4.0/

\begin{abstract}
Digital cameras are increasingly being used in educational settings for young children. In fact, more researchers are including photography activities into research involving children. This paper aims to describe how young children (aged six years) learned to use digital cameras and practiced composing photographs. Data were collected through photos taken by the children, video recordings and conversations with the children. This study shows the capability of children to be photographers and the potential of using photography in learning as well as in research involving young children. The introductory phase, practice session, guidelines and safety precautions used in this study can be a reference point for teachers, children and researchers willing to integrate the usage of digital cameras for learning and research purposes.
\end{abstract}

\section{Keywords}

Digital Cameras, Photography, Young Children

\section{Introduction}

Young children are exposed to visual images in many different ways since born, through watching television, reading and listening to story books, viewing digital photos, and noticing images in their surroundings. Due to the rich exposure to visual images in their lives, it is necessary that visual images are used to enhance children's learning and utilized in research. Educators and researchers are increasingly integrating photography activities into educational settings of early childhood and in research concerning young children (e.g., Einarsdottir, 2005; Blagojevic \& Thomas, 2008; Byrnes \& Wasik, 2009; Schiller \& Tillett, 2004; Pappamihiel \& Knight, 2016; Bell \& Cartmel, 2019). The increased usage of this digital tool by researchers is due to the possibilities of digital cameras and photography as powerful tools for learning, communication and research. 
Previous research recorded that the use of photography in classrooms has positively impacted various aspects of children's learning. Research indicated that photography activities that were integrated into language lessons had helped develop children's learning of language and literacy. Children were observed to benefit from such integration in which they improved their language and literacy skills (Britsch, 2010; Byrnes \& Wasik, 2009; Marinak, Strickland, \& Keat, 2010) whereby when children talked about their photos, they used richer vocabularies and lengthier sentences (Britsch, 2010); hence, stimulating their literacy knowledge and skills. Additionally, incorporating photography into science lessons can inspire children to engage in scientific investigation using different ways (Britsch, 2019).

As a research tool, photography permits children to express their views, thinking and understanding without being restricted to their verbal and written language competencies (Bakar, Yunus, Mohamed, \& Karim, 2020). This is specifically beneficial for young children who frequently struggle to communicate with others about what they have in mind due to having limited language proficiencies. An increasing number of researchers incorporated photography usage in research with young children through photo-talks (Serriere, 2010), photo-interviews (Cappello, 2005) and photo elicitation (Pyle, 2013; Ali-Khan \& Siry, 2014) to understand children's routine and life in school and home. When used as a data-collecting method, the photos composed by children provided a wealth of insights about children's lives and allowed children's "voices" to be "heard" and included into the studies. Including child-composed photographs into interviews did not only shed light into children's minds but help spark meaningful discussions with young children (e.g., Smith, Duncan, \& Marshall, 2005). In a study by Kirova and Emme (2008), conversation surrounding photos taken by the immigrant children themselves enabled them to convey information and facilitated the researcher to understand the children's family culture and their level of language development. Clearly, previous studies emphasized on the potential of visual modes used to facilitate young children to share their perspectives, views and express themselves.

When using digital cameras as a learning tool, of concern is children's competencies in using technology devices such as digital cameras (Pyle, 2013). However, it was proven that children are capable photographers (Barker \& Smith, 2012) provided that they were given sufficient time, practice and experience to work with the digital cameras to compose photos (Pyle, 2013; Britsch, 2019) prior to the actual photography task. Additionally, previous studies reported that children are proficient users of digital cameras and are able to self-compose photographs that benefit their learning processes (e.g., Blagojevic \& Thomas, 2008; Byrnes \& Wasik, 2009). Furthermore, researchers perceive digital photography activities as important information skills and literacy for young children (Ching, Wang, Shih, \& Kedem, 2006; Schiller \& Tillett, 2004). Hence, it is valuable to investigate how cameras can be introduced to young children to enable them to compose useful photographs. Moreover, there is little research 
that documents young children's learning process and practices of using digital cameras. This study is aimed at investigating the ways young children learn to use digital cameras and develop their photography skills, hence may add to the literature on the practices of young children in using digital cameras in classrooms.

\section{Methodology}

This study was part of a larger study that explored young children's creation of visual images using digital cameras during mathematics learning. Six children (aged six years) from a public preschool in Malacca (they were from the same classroom), Malaysia were selected as participants in this study. Over a four-week period, the researcher together with the children engaged in photography activities carried out three times a week. Altogether, twelve sessions occurred throughout the study to provide the children with enough opportunities to operate the digital cameras and produce photographs themselves. The study involved three phases; namely 1) introduction to digital cameras; 2) learning to operate cameras and practice photographing; and 3) composing photographs. Six digital cameras were allocated for this study in order for the children to have sufficient opportunity, time and experience in handling the digital cameras and produce photographs individually. The children were taught the basic operation of the digital camera and then they were provided with ample practice time. At the commencement of the study, the researcher ensured that consent was sought from all parents of the participants. The entire project was documented on video, audio-taping, photos and field notes. Photos taken by the researcher as well as the children were used to get insight into their photography skills.

\section{Findings}

This article documents the learning experiences of a group of young children including the challenges they encountered while operating the cameras.

\subsection{Phase 1: Introduction to Digital Cameras}

As an introduction, the researcher showed several examples of photographs that can be found on several media platforms including websites, magazines, newspapers and photo albums. The children were asked to name the tools or devices used to produce the photographs shown to them. The children easily identified cameras as the tool used to produce various types of photographs. The researcher continued with showing the children a digital camera. Excitedly, the children asked if they could use the cameras to take photos. The researcher agreed to allow the children to have the cameras in their hand, but must first recognize the parts of the cameras, then learn how the cameras functioned, and most importantly to follow the rules and safety precaution when having the cameras in hand.

Firstly, the researcher introduced the parts of the digital camera including the screen (viewfinder), shutter, lens, battery, and off and on button. Then the re- 
searcher demonstrated how several important buttons of the digital camera functioned. After that, the researcher handed over the camera to the children to give them the opportunity to have a closer look at the camera. They were also required to practice the function of different buttons including the on and off button and shutter release button. Several students took the opportunity to operate the cameras and took photos of their friends. Observing that the children were very excited and could not wait any longer to experience photographing objects themselves, the researcher reminded the children that they would be given the cameras on condition that they must always follow the safety rules and precaution procedures. The researcher emphasized that at all times when having the camera in hand, the children must remember to follow three important rules including 1) using the lanyard around the neck at all times; 2) never touch the lenses; and 3) staying still while taking pictures. These two former rules are crucial precaution and safety procedures to prevent the children from dropping, breaking or damaging the cameras. The latter procedure ensured the children could hold the cameras steadily when pressing the shutter and capturing good photos.

Prior to the introduction section, the researcher asked the children about their experiences of composing photos. A majority of the children highlighted that often times they were the subjects being photographed rather than being given the opportunity to be the photographer. Besides that, the majority of the children reported that usually adults are permitted to use the devices; Nadia informed that sometimes she had the opportunity to use her father's smart phone to take pictures. Norman commented despite the fact that his father owned a digital camera and frequently used them to capture family photos during vacation, children including himself and his siblings were not allowed to use them. Ali described the routines practiced by his parents during special events, holidays and vacations; concluding that adults frequently ensured that they captured good photos and kept them as valuable memories. He was not allowed to use the cameras but was often asked to view the pictures captured by his parents and requested to share his views about the photos (whether he loved the pictures or not).

\subsection{Phase 2: Learning to Operate Cameras and Practice Photographing}

After identifying the children's experiences with digital cameras and photography, the researcher invited the children to practice taking pictures. The aim of the practice session was to familiarize the children with the parts and functions of cameras as well as to develop their confidence in using the newly introduced technology device. Additionally, the researcher wanted to ensure that the children could independently use the digital cameras. Noticeably, some children offered assistance to his/her peers whenever they found others were having difficulty in operating the cameras. The children were asked to capture photos of numbers that can be found in the classroom. Excitedly, the children moved 
around the classroom and began their hunt. The children easily identified various numbers in the classroom. Some children showed their pictures to the researcher and continued their hunt.

Amy referred to the researcher as she noticed all the pictures she captured were missing. The researcher suspected that she had accidentally pressed the delete button causing all her previous images to be deleted. The researcher advised Amy to be extra careful with each button and function of the camera and also requested her to capture all the pictures again. Ruby also sought help from the researcher as she could not find the images she believed she had recorded using the camera. The researcher doubted whether she had pressed the shutter button hard enough during the photo shooting. The researcher then requested her to capture the pictures again. After capturing a few images, she viewed her photos and was satisfied that all the photos existed.

After the children had returned the digital cameras, the researcher than connected the cameras to the laptop and projected the photos in front of the classroom using a projector. Whilst projecting the photos, the researcher highlighted the outcome of each photo and listed several criteria that differentiated between "good", "acceptable" and "bad" photos. While a few children had captured "good" and "acceptable photos", a majority of the images were "bad photos". The researcher pointed out the technical errors that the children made when capturing pictures that resulted in "bad photos". The mistakes included not staying still when capturing images and standing too close or too far from an object when photographing. As can be seen in Figure 1(a), the images are blurry because the children might not have been standing still or their hands were shaky when capturing the photos.

The mistake that Amy made which resulted in the blurry photo of number 10 (as can be seen in Figure 1(b)) was standing too close to the object when capturing the photo. Clearly, the outcome of the "bad photos" was because either the children had shaky hands, not standing still when photographing or standing too close or too far from the objects.

Then, the researcher showed a few examples of "good photos" captured by their peers and discussed with the children several ways to ensure the production of "good" photos including ensuring the correct distance between the photographers and the subjects. The researcher also told the children that photos can be taken from different angles, hence advised the children to attempt several trials until they obtained a good outcome for the images.

\subsection{Phase 3: Composing Photographs}

Despite producing images of different quality (i.e., "good", "acceptable" and "bad photos"), the children had grasped the basic skills to operate the cameras and could press the shutter to capture pictures. After the researcher had explained the errors made that resulted in "bad photos" and described ways to produce "good" and "reasonable photos", the next task was posed. 


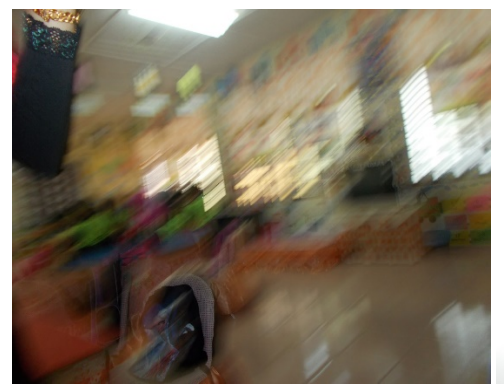

(a)

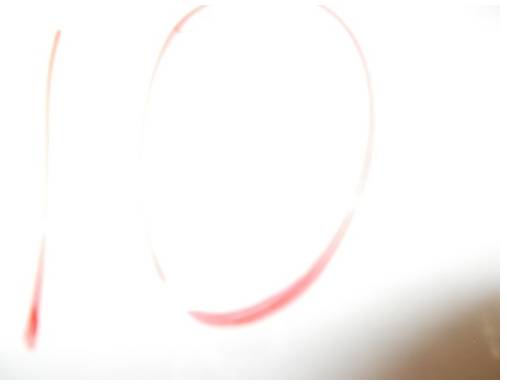

(b)

Figure 1. Examples of "bad photos" taken by the children. (a) Blurry photo of numbers on the classroom wall captured by Rozy; (b) Blurry photo of number 10 captured by Amy.

Firstly, the children were requested to get their friend's assistance to capture a photo of the child holding his/her name tag to help the researcher identify the photos taken by each child. Then the children were asked to identify objects that were circle in shape and recorded those images with their cameras. The children were observed to be more confident in capturing images; only a few children sought assistance from the researcher when they viewed that the photos were either too dark, bright or blurry. A few times, the researcher heard the children reminding each other to always obey the safety rules and procedures set up by the researcher at the start of the study.

The children's excitement increased as they were informed of different ways to document images. Hence, they experimented in various ways of capturing pictures by adjusting their distance from the objects and positioning themselves in various positions to capture the objects from distinct angles. As a result, the quality of the photos taken by the children improved gradually. Once the children were certain that they had "good" photos, they then proceeded to hunt for other objects.

Obviously, the children focused on two important aspects when reviewing the outcomes of their photos; 1) the objects captured, and 2) the quality of the images. The children ensured that the intended objects fitted nicely into the photo frames. In terms of photo quality, they were only satisfied when the images were clear and sharp; otherwise, the photos were deleted and retaken several times until they obtained "good" photos.

As can be seen in Figure 2(a), Deliyana captured the round table very clearly. The researcher noticed that she adjusted her distance from the object several times until she was satisfied that the entire table was captured.

As for Nadia, she found the projector lens that was in a circle shape and carefully captured the image. Notice that the image was positioned nicely at the center of the frame (see Figure 2(b)).

\section{Discussion of Findings}

\subsection{Young Children Are Capable Photographers}

The findings in this study acknowledged children's capability in handling digital 


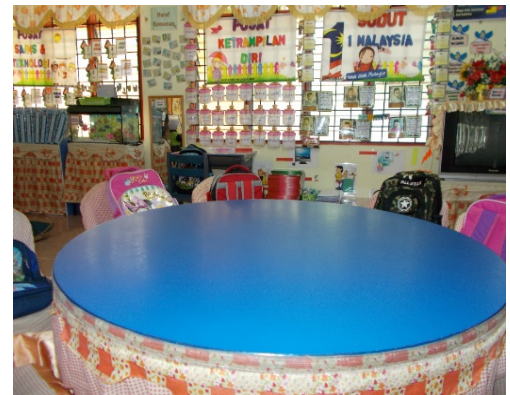

(a)

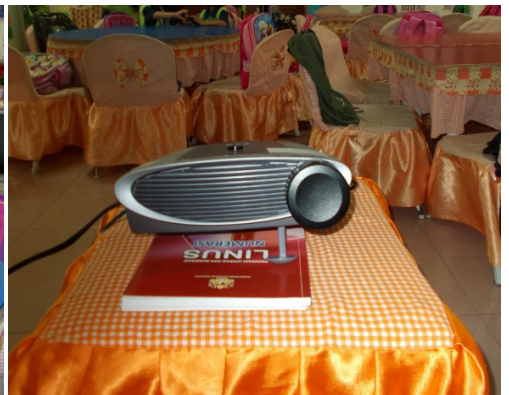

(b)

Figure 2. Examples of photos that are circle in shape. (a) Photo of round table captured by Deliyana; (b) Photo of cover lens captured by Nadia.

cameras; hence, in agreement with previous research that indicated young children as capable photographers (Barker \& Smith, 2012). As asserted by Couse and Chen (2010), children are proficient users of technology as they use technology devices easily and independently. Additionally, the advancement in technology that have resulted in the production of smaller sizes of cameras that are powerful, yet reasonably priced and practical to use, permitted even young children to operate the digital cameras (e.g., as young as six years old as in this study). In fact, the growing availability of child friendly cameras has made these tools easy and practical to use by children (Orr \& Suh, 2013). As observed in this study and in line with previous studies, children learn to operate cameras and produce photos after watching a demonstration by adults and after learning the camera functions shown by peers (Husbye, Buchholz, Coggin, Powell, \& Wohlwend, 2012).

\subsection{Keys to Develop Young Children's Photography Skills}

This study found that during the children's early experiences of using digital cameras, there were great differences in the children's composition of photos. The photographs taken by the children can be categorized into 1) "good" photos, 2) "acceptable" photos, and 3) "bad" photos. It is not surprising that there were challenges faced by the children when operating the digital cameras. Considering the fact that a majority of the children had no experience working with digital cameras and were only recently introduced to the digital cameras, several accidents may have occurred (e.g., as happened to Amy and Rozy). However, with proper assistance and following the given advice as well as helpful information to capture "good" photos, they finally produced quality images as the final products. The children's effort to capture the same objects several times showed their concern on the content and quality of the images they had taken.

Three important aspects implemented in this study include 1) the precaution and safety rules, 2) knowledge and skills in composing useful photos, and 3) sufficient exposure and practice are the keys to develop photography skills among young children. It is vital to have the precautionary rules introduced at the start of the study and constant reminders throughout the study to ensure the safety of 
both photographer and device. Equally important is that the children were provided with enough time, opportunity and practice to help develop their photography skills (Pyle, 2013). Furthermore, children can produce better pictures and become proficient photographers when they are equipped with the knowledge and skills to compose useful photos (what makes good and bad photos).

When introducing a new device to young children, giving them the opportunity to explore the camera functions and providing sufficient practice in taking photos enable the children to become better photographers. As recommended by Clements and Sarama (2002), children should be exposed to technology in a developmentally appropriate way. Considering the fact that a majority of the children had never experienced taking photos independently, making errors and capturing dark and blurry photos are acceptable. With sufficient practice, the children learnt from their mistakes and finally captured good photos. As highlighted by Bauer and Kenton (2005), young children should be given rich experiences and opportunities to help them obtain relevant knowledge and skills for their learning. It is through exploration, sufficient experiences in handling digital cameras and opportunities to improve their photography skills that the children in this study learnt to become better photographers. Throughout the study, the children showed excitement when having the digital cameras in hand and while photo shooting various objects. The composition of a great number of photos and their efforts in improving the quality of photos showed that photography activities did not only provide excitement to children but motivated them to produce good and quality work as the final outcome (Dragan, 2008).

\section{Conclusion}

This study acknowledged children as competent users of technology, as evident in the children's capability to operate the digital cameras successfully. Additionally, the children's composition of useful and good photos recognized young children as capable photographers. It is important that the young children were constantly reminded of the safety rules throughout the study to ensure they handled the devices safely and successfully.

Photos are not only a means to bring back memories of special moments, events and occasions, but serve as effective communication between young children and adults. This study supported the statement of a previous study stating the potential of using photography by young children as a means for both research and learning in an early childhood setting. Given sufficient time and practice, children could explore the use of the device and familiarize themselves with the camera functions. This is important to ensure the successful use of the newly introduced device to the children.

The safety precaution procedures and rules as well as the phases involved in introducing the digital cameras to the children as implemented in the current study may serve as useful reference for both teachers and researchers when incorporating digital cameras and photography activities into young children's 
learning and as a useful tool for data collection in research. Additional keys to ensure children can be capable photographers include providing children with sufficient exposure and practice using cameras as well as equip children with the knowledge and skills to compose useful photos.

Further research is required to determine new possibilities and opportunities that will nurture young students' capability in creating visual modes to support their learning in various subjects. Furthermore, the inclusion of conversation surrounding photos in research enables children to convey important messages about their lives to adults. Additionally, it is vital that the children's "voices" be heard to enable researchers to acquire rich insight into children's views, perspectives and understanding of their lives.

\section{Acknowledgements}

This research was supported by grants provided by the Universiti Kebangsaan Malaysia (GGPM-2019-011) and (GG-2019-061).

\section{Conflicts of Interest}

The author declares no conflicts of interest regarding the publication of this paper.

\section{References}

Ali-Khan, C., \& Siry, C. (2014). Sharing Seeing. Exploring Photo-Elicitation with Children in Two Different Cultural Contexts. Teaching and Teacher Education, 37, 194-207. https://doi.org/10.1016/j.tate.2013.08.004

Bakar, K. A., Yunus, F., Mohamed, S., \& Karim, A. A. (2020). Addition Concept through the Lenses of Young Children: Creating Visual Representation with Digital Cameras. Eurasia Journal of Mathematics, Science and Technology Education, 16, Article No. em1854. https://doi.org/10.29333/ejmste/7950

Barker, J., \& Smith, F. (2012). What's in Focus? A Critical Discussion of Photography, Children and Young People. International Journal of Social Research Methodology, 15, 91-103. https://doi.org/10.1080/13645579.2012.649406

Bauer, J., \& Kenton, J. (2005). Toward Technology Integration in the Schools: Why It Isn't Happening. Journal of Technology and Teacher Education, 13, 519-546.

Bell, K., \& Cartmel, J. (2019). Creating a Vocabulary about School-Age Childcare Using Photography. International Journal of Qualitative Methods, 18, Article ID: 1609406918811488. https://doi.org/10.1177\%2F1609406918811488

Blagojevic, B., \& Thomas, K. (2008). Young Photographers. Young Children, 63, 66-72.

Britsch, S. (2010). Photo-Booklets for English Language Learning: Incorporating Visual Communication into Early Childhood Teacher Preparation. Early Childhood Education Journal, 38, 171-177. https://doi.org/10.1007/s10643-010-0412-2

Britsch, S. (2019). Exploring Science Visually: Science and Photography with Pre-Kindergarten Children. Journal of Early Childhood Literacy, 19, 55-81. https://doi.org/10.1177\%2F1468798417700704

Byrnes, J., \& Wasik, B. A. (2009). Picture This: Using Photography as a Learning Tool in Early Childhood Classrooms. Childhood Education, 85, 243-248. https://doi.org/10.1080/00094056.2009.10523090 
Cappello, M. (2005). Photo Interviews: Eliciting Data through Conversations with Children. Field Methods, 17, 170-182. https://doi.org/10.1177\%2F1525822X05274553

Ching, C. C., Wang, X. C., Shih, M. L., \& Kedem, Y. (2006). Digital Photography and Journals in a Kindergarten-First-Grade Classroom: Toward Meaningful Technology Integration in Early Childhood Education. Early Education and Development, 17, 347-371. https://doi.org/10.1207/s15566935eed1703 3

Clements, D., \& Sarama, J. (2002). Teaching with Computers in Early Childhood Education: Strategies and Professional Development. Journal of Early Childhood Teacher Education, 23, 215-226. https://doi.org/10.1080/1090102020230305

Couse, L. J., \& Chen, D. W. (2010). A Tablet Computer for Young Children? Exploring Its Viability for Early Childhood Education. Journal of Research on Technology in Education, 43, 75-96. https://doi.org/10.1080/15391523.2010.10782562

Dragan, P. B. (2008). Kids, Cameras, and the Curriculum: Focusing on Learning in the Primary Grades. Portsmouth, NH: Heinemann.

Einarsdottir, J. (2005). Playschool in Pictures: Children's Photographs as a Research Method. Early Child Development and Care, 175, 523-541.

https://doi.org/10.1080/03004430500131320

Husbye, N. E., Buchholz, B., Coggin, L. S., Powell, C. W., \& Wohlwend, K. E. (2012). Critical Lessons and Playful Literacies: Digital Media in PK-2 Classrooms. Language Arts, 90, 82-92.

Kirova, A., \& Emme, M. (2008). Fotonovela as a Research Tool in Image-Based Participatory Research with Immigrant Children. International Journal of Qualitative Methods, 7, 35-57. https://doi.org/10.1177\%2F160940690800700203

Marinak, B. A., Strickland, M. J., \& Keat, J. B. (2010). A Mosaic of Words: Using Photo-Narration to Support All Learners. Young Children, 65, 32-36.

Orr, J., \& Suh, J. (2013). A Picture Is Worth 100 Math Ideas. Teaching Children Mathematics, 19, 458-460. https://doi.org/10.5951/teacchilmath.19.7.0458

Pappamihiel, N. E., \& Knight, J. H. (2016). Using Digital Storytelling as a Language Experience Approach Activity: Integrating English Language Learners into a Museum Field Trip. Childhood Education, 92, 276-280. https://doi.org/10.1080/00094056.2016.1208005

Pyle, A. (2013). Engaging Young Children in Research through Photo Elicitation. Early Child Development and Care, 183, 1544-1558. https://doi.org/10.1080/03004430.2012.733944

Richards, R. D. (2019). Young Children's Photography within Collaborative Research. In Ilene, R. B., Michael, J. B., \& Colette, G. (Eds.), Participatory Methodologies to Elevate Children's Voice and Agency (Vol. 1, pp. 317). Charlotte, NC: Information Age Publishing.

Schiller, J., \& Tillett, B. (2004). Using Digital Images with Young Children: Challenges of Integration. Early Child Development and Care, 174, 401-414. https://doi.org/10.1080/030044303200015344

Serriere, S. C. (2010). Carpet-Time Democracy: Digital Photography and Social Consciousness in the Early Childhood Classroom. The Social Studies, 101, 60-68. https://doi.org/10.1080/00377990903285481

Smith, A., Duncan, J., \& Marshall, K. (2005). Children's Perspectives on Their Learning: Exploring Methods. Early Child Development and Care, 175, 473-487. https://doi.org/10.1080/00377990903285481 